\title{
DIAGNOSIS AND TREATMENT OF LOCALIZED NEUROPATHIC PAIN SECONDARY TO KERATOACANTHOMA CENTRIFUGUM MARGINATUM
}

\author{
Sánchez Tabernero Á., Gómez Fernández M., Lomo Montero F.J., Álvarez \\ Gallego E., Sánchez Hernando V.J., Vega Cruz M.S. \\ Complejo Asistencial de Zamora, Dept of Anaesthesiology \& Pain Medicine, Zamora, Spain
}

BACKGROUND:We report a case of pain secondary to keratoacanthoma centrifugum marginatum (KCM), which was diagnosed with screening tool for the diagnosis of neuropathic pain.

CASE REPORT: 54 year old male with a history of type 2 diabetes mellitus, with pain secondary to $\mathrm{KCM}$. He was treated with 5-fluorouracil topical and acitretin, intralesional methotrexate, topical imiquimod $5 \%$, retinoids, radiotherapy and curettage. Pain intensity by visual analog scale (VAS) was 7 , accompanied by electric discharge in the first finger and back of the right hand in relation to the cures, and paresthesias in this area. For diagnosis, screening tool was used. He was treated with lidocaine patch $5 \%$, and tramadol $50 \mathrm{mg}$ one hour before to cures. The patient showed an improvement of sensory symptoms and pain (VAS 3).
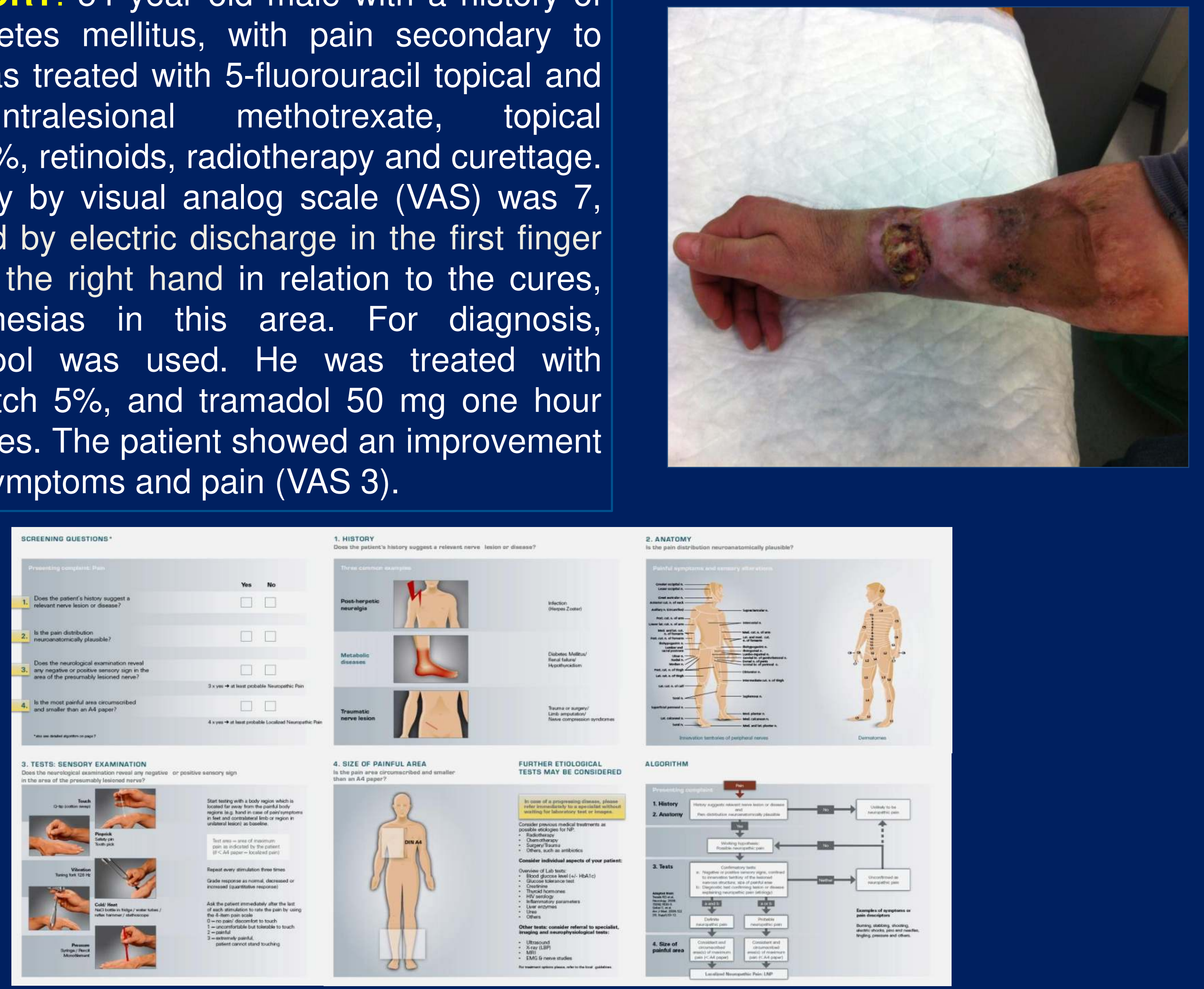

DISCUSSION: KCM is a rare variant of keratoacanthoma. To date, only 40 cases have been reported worldwide ${ }^{1}$. In our case, the patient had a localized neuropathic pain, that was easy to detect using a new tool for detection of neuropatic pain and the subtype, localized neuropathic pain, the screening tool. It consists of four questions, in addition to the information regarding each of these issues, and a detailed algorithm. A spanish version and a version in english are available today in wallet card form ${ }^{2}$.

\section{REFERENCES:}

1. Yang $Y, X u Y$, Wang $L$, et al. Two cases of giant keratoacanthoma centrifugum marginatum accompanied by $\alpha$-human papillomavirus infection. Int J Dermatol. 2015 Aug;54(8):951-4.

2. Mick G, Baron R,Correa G, et al.Is an easy and reliable diagnosis of localized neuropathic pain (LNP) possible in general practice? Development of ascreening tool .Abstract 3145; XXI WCN2013; Sept 2013. 